Archived version from NCDOCKS Institutional Repository http://libres.uncg.edu/ir/asu/

\title{
Appalachľan
}

B O O N E, N O R T H C A R O L I N A

\section{Pursuing Fitness: How Dialectic Goal Striving And Intersubjectivity Influence Consumer Outcomes}

\author{
By: Pia A. Albinsson, PhD, B. Yasanthi Perera, PhD, and G. David Shows, DBA
}

\begin{abstract}
Consumers increasingly engage expert service providers in their goal pursuits. While the literature focuses primarily on goal attainment, this presents just one stage of extended goal striving. Using Bagozzi and Dholakia's (1999) goal-striving framework as the foundation, this qualitative research examines the client-trainer interactions in the goal-striving process. We find that goal-striving with the aid of expert service providers entails intersubjectivity. The consumer wrestles with multiple understandings of fitness to determine and pursue a goal. This considers the individual's perceptions and desires, cultural and societal discourses, and trainer's views. Effective goal pursuit requires shared understanding between client and trainer. It entails a moment of release when consumers accept their inability to translate goals into actions alone. This occurs at multiple stages of the process. By examining the influence of service providers on goal-strivers, this research extends our understanding of goal-striving as an accepted agreement between the Self and Other.
\end{abstract}

Albinsson, Pia A., B. Yasanthi Perera, and G. David Shows (2016), "Pursuing Fitness: How Dialectic Goal Striving and Intersubjectivity Influence Consumer Outcomes," Consumption, Markets and Culture, http:// dx.doi.org/10.1080/10253866.2016.1 172213. Publisher version of record available at: https://www.tandfonline.com/doi/abs/10.1080/10253866.2016.1172213 


\title{
Pursuing Fitness: \\ How Dialectic Goal Striving and Intersubjectivity Influence Consumer Outcomes
}

\author{
Pia A. Albinsson, $\mathrm{PhD}$ \\ Appalachian State University \\ Walker College of Business \\ Department of Marketing \\ Peacock Hall 4101 \\ ASU Box 32090 \\ Boone, NC 28608-2090 \\ Phone: 828-262-6197 \\ Fax: 828-262-6192 \\ Email: albinssonpa@appstate.edu* \\ B. Yasanthi Perera, PhD \\ Brock University \\ Goodman School of Business \\ Department of Organizational Behaviour, \\ Human Resource Management, Entrepreneurship and Ethics \\ 500 Glenridge Avenue \\ St. Catharines, ON L2S 3A1 \\ Phone: $905.668 .550 \times 6703$ \\ Fax: 905.641.8068 \\ Email: bperera@brocku.ca \\ G. David Shows, DBA \\ Appalachian State University \\ Walker College of Business \\ Department of Marketing \\ Peacock Hall 4101 \\ ASU Box 32090 \\ Boone, NC 28608-2090 \\ Phone: 828-262-2135 \\ Fax: 828-262-6192 \\ Email:showsgd@appstate.edu \\ * contact author
}

- To cite: Albinsson, Pia A., B. Yasanthi Perera, and G. David Shows (2016), "Pursuing Fitness: How Dialectic Goal Striving and Intersubjectivity Influence Consumer Outcomes,” Consumption, Markets and Culture, http://dx.doi.org/10.1080/10253866.2016.1172213

Acknowledgements: The authors extends their appreciation to the editor - Jonathan Schroeder, and the three anonymous reviewers for their insightful comments. In addition, the authors would 
like to thank Kelly Tian, Linda Price and Russell Belk for their guidance and support with earlier renditions of this article.

\title{
Pursuing Fitness:
}

\section{How Dialectic Goal Striving and Intersubjectivity Influence Consumer Outcomes}

\begin{abstract}
Consumers increasingly engage expert service providers in their goal pursuits. While the literature focuses primarily on goal attainment, this presents just one stage of extended goal striving. Using Bagozzi and Dholakia’s (1999) goal-striving framework as the foundation, this qualitative research examines the client-trainer interactions in the goal-striving process. We find that goal-striving with the aid of expert service providers entails intersubjectivity. The consumer wrestles with multiple understandings of fitness to determine and pursue a goal. This considers the individual's perceptions and desires, cultural and societal discourses, and trainer's views. Effective goal pursuit requires shared understanding between client and trainer. It entails a moment of release when consumers accept their inability to translate goals into actions alone. This occurs at multiple stages of the process. By examining the influence of service providers on goal-strivers, this research extends our understanding of goal-striving as an accepted agreement between the Self and Other.
\end{abstract}

Keywords: intersubjectivity; witnessing; goal pursuit; identity; dialectical goal setting and goalstriving; personal training 


\section{Pursuing Fitness:}

\section{How Dialectic Goal Striving and Intersubjectivity Influence Consumer Outcomes}

\section{Introduction}

The fulfillment of a personal goal carries the inference of individual personal initiative, a singular struggle in the pursuit of achievement. Many examples in popular culture describe persons lifting themselves "by their bootstraps" to achieve their goals, succeeding by what is described as sheer force of will. Society lauds those like Steve Jobs of Apple and Jeff Bezos of Amazon for the ability to move their dreams from the esoteric to the material. Besides other talents, successful people have the ability to transform desires and goals to actionable phases. Described by Bagozzi and Dholakia (1999) as action planning, these goal-strivers effectively address the question, “How can I achieve my goals?” (Bagozzi and Dholakia 1999, 20). Achievers, perhaps in contrast to others, can effectively visualize the steps required for success and the discipline to pursue the actions, sometimes to the exclusion of all else.

We tend to believe that our goals arise from our personal ideals and desires. However, culture, specifically interactions with others as well as societal ideals and expectations, partially influence the goals. An example is the pursuit of material assets, or becoming attractive. The pursuit of fitness is unique because, over history, society has constantly redefined what fitness entails. Depending on the historical period, society has described a fit person as corpulent, thin, heavily muscular, unmuscular, exhibiting sloth, highly active, an eater of meat and potatoes, a vegetarian, and all stages in between. As society moves from one age to another, the concept of fitness and its purpose as a promotor of health and a desirable life has evolved. Our current understanding of what entails "fit” includes a movement away from obesity and the promotion of an active lifestyle supplemented by vigorous exercise. 
Fitness pursuits, particularly those relating to weight loss, are entrenched in the North American cultural discourse perhaps largely due to social and medical implications of obesity. Phillips (2005, 525) notes that the "North American popular culture can be characterized by its obsession with fitness and exercise.” Confirmation is in recognizing the thriving fitness industry in the United States. In 2015, the industry employed 259,000 individuals and generated estimated revenues in excess of 10 billion dollars (IBISWorld). Additionally, over the past three decades, the number of U.S. gym facilities increased from 11,804 to over 35,000 and number of gym membership purchased rose from 17.3 million to 58 million (IHRSA Annual Trend Report 2012; Statistica 2015). This trend is likely to continue with IBISWorld (2015) estimating the existence of 70,000 gym facilities by year 2020 .

Fitness goals can be termed as persistent goals pursuits because they are challenging as “smooth action toward goal attainment is impeded” (Bagozzi and Dholakia 1999, 31) and reaching the desired outcome requires long-term effort. Indeed, while unprecedented numbers of consumers now engage in fitness-related services, only $50 \%$ of those who embark on an exercise program persevere with their efforts beyond six months (Dishman and Chubb 1990).

Increasingly, consumers within the middle-income bracket are utilizing personal training, once regarded as a service for celebrities and the wealthy, in achieving their fitness goals (Smith Maguire 2008). Currently over 6.5 million U.S. consumers use personal training services (IHRSA, as cited by IBIS World 2015).

This unique characteristic of fitness as bound by time and culture provides an interesting study in the pursuit of goals. When pursuing fitness, the goal-striver must contend with defining his or her fitness goal in terms of health, shape, mental image, and other body desires measured against our current culture definition of a “fit” body. Thus, fitness goals, to some extent, require 
the consumer to pursue an objective that is subjective in nature. Due to this subjectiveness, the consumer may be unable to translate a fitness goal into action. Current discussion in goal fulfillment has yet to consider when consumers' efforts towards fulfilling a desire fall short, perhaps through the failure to translate desire into an effective action plan, or inability to understand the goal objective due to differing interpretations of the objective that exist (Borgerson 2010).

When consumers realize that they may fail in their goal pursuit, they face a choice; accept the failure and move on, or increase their effort in order to succeed. Increased effort can include the reformation of an action plan or the acceptance of others' assistance to fulfill the dream. To achieve fitness goals, the pursuer may engage the assistance of another party. However, as DePaulo and Fisher $(1980,23)$ note, “a person deciding whether to ask for help is almost always in conflict.” This statement underlies the inner struggle when the desire to achieve a goal requires the intervention of another.

Exchange theory postulates that in every exchange, something of equal or greater value, literally or figuratively, changes hands (Solomon, Marshall, and Stuart 2016). This could mean one surrenders his or her command over a situation and must subordinate one's will to another in order to succeed. In this regard, anyone taught, coached, or trained accepts the superior understanding of another. An example is in the movie “The Karate Kid”; Miyagi, the expert/teacher, gives Daniel, the protagonist/ student, a series of exercises with no explanation of how they will help the latter reach his ultimate goal. We can extend this example to the pursuit of fitness goals where a personal trainer may prescribe that the consumer use drills and exercises that contain no clear purpose to the latter. This conflict can only be resolved either through the refusal to accept the help of the teacher, or releasing the conflict and accepting the teacher in his 
or her role. In the latter case, the consumer, in his or her interactions with the personal trainer, must grapple with and come to a personal understanding of what being fit entails, usually trusting the subjective understanding offered by their trainer. This conflict of subjectivities involves the idea of intersubjectvity.

\section{Intersubjectivity in determining "fit"}

Intersubjectivity refers to the meaningful engagement of subjects and to how we make sense of the world and each other together (DeJaegher 2015). Inherent in the definition is that our understanding of the world and everything around us comes from communication through shared encounters. These social encounters affect us; they essentially transform us and our epistemological understanding of the world (DeJaegher 2015). Our understanding of the world is comprised of the interaction between three themes: the Self, or owned body, Freedom, and the Other (Borgerson 2010). The Self is our personal position and perspective of the world and how we see it; Freedom is our participation in the world, and the Other is our understanding of others in the universe, thereby rejecting solipsism (Borgerson 2010), the theory that only the Self exists.

Intersubjectivity, in relation to consumer culture and organizational structures, largely concerns conflict (Borgerson 2010). The actor defines and redefines ideas and entities in various interactions, with eventual understandings consummated by one theme, prevailing over others. In the case of fitness, there are multiple understandings of what fit entails. Society has an idealized version that is widely shared through advertising, and entertainment outputs, as well as by various public figures such as celebrity fitness instructors and weight loss experts. The actor “encounters” these perspectives, as well as those posited by individuals and groups in their private lives such as spouses, partners, and even those in a place of worship. The actor will grapple with these, at times, conflicting perspectives at different points in time to develop his or 
her idea of fitness. However, once the individual finalizes his or her understanding, there is the danger of closure, where the predominant intersubjective understanding of a concept resists actions to reconsider its meaning.

In defining “fit” three conflicting ideals challenges us. First, there is society’s consideration of the concept. The notion of fitness applies not just to shape, but also to beauty and physical attributes. Based on images displayed in the media, for men, the current notion of fitness entails a flat "six-pack" stomach and V-shape chest, while for women; it is an hourglass shape and other enhancements. The second is the trainer's idea of fitness. Trainers are educated in human anatomy so their understanding of fitness is intersubjectively conditioned through their training. Finally, there is the consumer who considers consumer culture's vision of fitness, the trainer's view, and his or her own personal view to choose which one is most viable. Thus, what is at play here is the interaction between the self and the culture, freedom (choice of vision), and the Other (the trainer).

This paper considers the phenomenological crisis between the individual's desire to achieve a goal and the acceptance of an intersubjective vision to further its completion. We posit that consumers may have to accept the reformation of their action plan by an external party, or abandon their personal plan entirely and completely accept another in order to achieve a personal objective. In addressing the research question, "How do consumers and service providers in extended service encounters negotiate goal setting and goal pursuit?” we examine two unique struggles to formulate the vagaries of a vision into a plan; a dyadic interaction between a consumer and one’s self, and an interaction between a consumer and another. Limited studies have explored the influence of service providers on consumers' goal striving efforts (e.g. Fischer et al. 2007; Fischer et al. 2009; Beruchashvili and Moisio 2013; Moisio and Beruchashvili, 2010; 
Zayer et al. 2015). This literature is currently limited to fitness activities, dieting, sought parenthood, and general well-being (Crossley, 2006; Fischer et al., 2007; Fischer et al., 2009; Sassatelli, 1999; Moisio and Beruchashvili 2010; Huang et al. 2015). Fisher et al. (2007) explored consumers’ pursuit of parenthood through artificial reproductive technologies. However, one could argue that goal attainment was largely dependent of factors outside the consumers' control in their research context. A consumer may be determined and mentally very much engaged in the process, ultimately biology and medical technology play a key role in goal attainment. In another study, Fischer et al. (2009) examined the relationship between personal trainers and clients and how their three discerned relationships of "trainers as partner, trainer as priest, and trainer as tormentor” affect the success and failure of goal attainment in the coproduction experience. Although the current research also examines the interactions between the client-trainer dyad in pursuit of fitness goals, we specifically examine this process across all goal striving stages in Bagozzi and Dholakia’s (1999) framework. Doing so is important because goal striving in a consumer intensive service encounter involves much more than assessing factors leading to goal success or failure. In this research, we extend the extant literature on persistent goal pursuits that utilize the aid of experts with specialized knowledge. In the following section, we provide an overview of the relevant literature.

\section{Goal pursuit}

We limit our examination of goal pursuits to those that stem from volitional behavior where the consumer forms a goal intention by consciously determining for what he or she strives (Bagozzi and Dholakia 1999). Bagozzi and Dholakia (1999) describe the movement toward a goal as a series of coordinated steps. First there is goal setting, which pertains to the question "What are the goals I can pursue, and why do I want to pursue them?” Next is the formation of a goal 
intention that entails asking, "What is it for which I strive?" Third is the action planning phase where the goal pursuer asks the critical question “How can I achieve my goal?” After planning, there is the action initiation and control, which questions the success or failure in one's progress towards the goal. At this stage, consumers may choose to protect their goal intention and continue with goal striving or abandon it. The final evaluative step is goal attainment or failure, which asks, “To what degree have I achieved or failed to achieve my goal?” These five stages can be categorized into two broad phases, goal setting and goal striving, which is the commitment in principles to a series of actions that will achieve success (Bagozzi and Dholakia 1999).

Self-set goals comprise a three-tiered hierarchy of superordinate, focal, and subordinate goals (Bagozzi and Dholakia 1999). While the focal goals indicate for what one strives, the superordinate goals answer, "Why do I want to achieve that for which I strive?” and the subordinate goals address how the consumer can achieve the focal goals. Once an individual sets a goal, he or she must engage in multiple other goals in order to achieve the initial goal. In the current research, the participant consumers had set the focal goal of becoming fit for a variety of reasons, which represent their superordinate goals (See Figure 1). While in the realm of fitness, the focal goal may vary depending on the individual. For example, Person A may speak of “losing x pounds” whereas Person B may speak of “bench pressing x pounds.” In order to reach this focal goal, they may choose to engage in multiple subordinate goals including exercise and diets. Our research examines consumers’ decisions to engage a personal trainer in order to achieve their focal goal of "becoming fit.” Guided by our previously stated research question, our study focuses on the goal striving stage, the process that occurs once the consumer has accepted a goal and starts to focus on its planning and implementation. Prior research in 
consumer intensive context such as personal training and health care (e.g. Fischer et al. 2009; Zayer et al. 2015) has largely examined consumer perceptions of success and failure, which pertains to the final stage of Bagozzi and Dholakia’s (1999) framework. In contrast, our research examines the “Action initiation and control” stage of the Bagozzi and Dholakia (1999) framework as well as the gap between the "Formation of a goal intention" and "Action planning.” In particular, when viewed through the lens of intersubjectivity, we posit that a conflict is contained in the gap between the "Formation of a goal intention" and "Action planning” stages.

\section{Conflicts}

Goal setting entails a consideration of an individual's internal processes such as cognitions and emotions. These aspects, in turn, are influenced by the individual's personal worldviews and cultural and familial discourses. Within the sociological concept of witnessing which involves “how we come to know through the experiences and reports of others” (Borgerson 2010, 78), the goal-setter is influenced by two visions (Oliver, 2004). The first is subjectivity, or one's sense of self, the "I" as an agent in the environment. In the concept of witnessing, subjectivity entails viewing with a sense of an eyewitness to facts at hand. It entails understanding the complete self in relation to the seen universe. The concept of subject position however pertains to the understanding of oneself in a historical and social context in society. Subject position is bearing witness to the unseen in society that influences the societal condition in which we live in (Oliver 2004). Thus, while subjectivity entails the detailed understanding of a desired fitness goal from the subject's position, which includes social position, a development disability, or other condition may affect one’s subjectivity, or one’s sense of self as an active agent. 
Culture also influences goal setting when the individual defines his or her chosen goal in relation to the desired cultural standard. Fischer et al. $(2007,126)$ suggests, "Cultural resources...can help regulate the tactics consumers choose and direct the ways in which consumers plan their efforts.” With respect to cognition, consumers assume both external and internal fitness goals (Smith Maguire 2006). From an internally driven goal perspective, exercise becomes a means for “one’s body to satisfy desires for control, authenticity, and pleasure” (Smith Maguire 2006, 126). Internal motivations include the desire for "improved health, social contact, and increased energy” whereas external motivations, which often fall within a sociocultural market-mediated discourse as "keys to social and occupational success," entail achieving a "fit and sexy look and to become more confident" (Smith Maguire 2006, 120, 126). We posit the presence of two forces: the consumer's internal motivation for garnering a richer life experience through a healthier lifestyle and external motivations that fall within socio-cultural exchanges. The internal motivations entail the drive for control and authenticity including a greater command of one's body and mind, whereas the externally derived motivation is for others' acceptance through achieving the societal ideals of fitness and what is sexually appealing (Smith Maguire 2006). The potential tension between internally-driven and externally-driven motivations presents another layer of complexity that the individual must grapple with in the pursuit of his or her goal.

In terms of the conflict referenced earlier, the gap between the formation of a goal intention and action planning contains the consumer's capacity to conceptualize a goal outcome as the result of the performance of certain tasks. Bagozzi (1992) identifies three means of appraisal that one utilizes to select these means. First, the consumer appraises his or her ability to exercise control over the means to achieve the goal. This pertains to self-efficacy (Bandura 
1997), the notion of whether or not one is confident in one's ability to succeed. Second, the consumer appraises whether the selected action, if performed, will lead to the desired outcome. Finally, the consumer appraises whether the goal-directed behavior is pleasant or unpleasant. We can relate the consumer's appraisal of the various means of achieving the goal as well as the tension between his or her internal and external motivations to intersubjectivity. In action planning, the possibility exists of a challenge between the consumer's commitment to fitness and his or her acceptance of the actions that society accepts as promoting success. In the internal bargaining between the acceptance of intersubjective definitions of fitness and a consumer's capacity to meet those definitions with supporting actions is his or her ability in correctly interpreting the difference. This calls for the concept of the third, or a vantage point outside of self and others that can view the intersubjective conversation between ourselves (Benjamin 2004). In viewing the conversation in thirdness, the consumers may accept their self-view of the action plan to be insufficient to achieve the subjective view of fitness. At this point, they must decide to accept failure or be willing to let go of their own point of view and accept another to achieve success. This “letting go of the self” has been called surrender (Ghent 1990, 8) and refers to the willingness to recognize another point of view. Ghent $(1990,109)$, however, characterized one of the features of surrender as being "not a voluntary activity" and maintained, “One cannot choose to surrender.” Thus, another definition containing a willingness to accept “surrender” is more acceptable. While Western culture typically construes surrender as giving up (Branscomb 1993), surrendering in this instance aligns with Gunnlaugson and Moze’s (2012) interpretation as a shift from a personal consciousness to a transpersonal state of consciousness, where the personal self is relaxed and more willing to accept a wider understanding. This include the voluntary acceptance of differing points of view. Surrendering is a movement towards an 
orientation of learning (Moze 2009; Tiebout, 1949), releasing one from defenses that would promote a lessening in openness to new possibilities. We define this voluntary acceptance of another point of view in our work as the moment of release, the defining moment when, to achieve success, one releases oneself from the constraints of personal opinions and recognize other points of view as more acceptable and reasonable. This research contributes to the extant literature by explicating what occurs in goal striving, not only with regards to the self and culture, but also in regard to an "other," the personal trainer. The following section provides an overview of the history of fitness in consumer culture.

\section{The roots of fitness in consumer culture}

The original understanding of fitness concerned its importance to the success of a given culture. The Persian Empire mandated fitness among their people to expand their empire (Dalleck and Kravitz 2002). The Spartans maintained fitness programs for their males to become fit soldiers, and required their females to be fit to produce healthy offspring (Dalleck and Kravitz 2002).

While fitness was a known part of life in the US, due to the concerns for survival during consolidation of the states, it was relegated to an interested few. The U.S. initiated physical education programs in schools after 1918 as nearly one out of every three men drafted for WWI were unfit to serve (Barrow and Brown 1988; Wuest and Bucher 1995). Later, during World War II, the U.S. either rejected or assigned half of all draftees to non-combat positions due to their poor fitness (Rice, Hutchinson, and Lee, 1958). In the 1950's studies found that 60 percent of American children failed fitness tests, as opposed to five percent of European children (Kraus and Hirschland 1954). This situation was unacceptable during the highly competitive Cold War years so, in 1956, President Eisenhower created the President's Council on Youth Fitness to 
educate young citizens of the dangers of low fitness levels. President Kennedy subsequently expanded this effort to promote the health benefits of fitness to all age groups.

In terms of consumer culture, during this period Jack LaLanne developed a program that initiated the modern fitness movement. LaLanne, a self-described “junk food junkie” who suffered from severe headaches and a bad temper, experienced a revelation at age fifteen when listening to Paul Bragg, the health food pioneer, talking about health and nutrition. LaLanne changed his eating habits, started exercising, and developed his mission in life, believing that a "physical culture and nutrition is the salvation of America” (Luther 2011, 1). In 1936, LaLanne opened the first health and fitness club in California and subsequently created the first leg extension equipment, pulley machines, and weight selectors. He encouraged women to exercise thereby countering the strongly embedded cultural message that exercising would result in women appearing masculine and unattractive. In 1953, LaLanne broadcast his first exercise show on television at the exact time the U.S. considered fitness to be important to the future of the country.

Over the next 50 years, the concept of fitness became integrated into consumer culture. The number of fitness clubs in the U.S. increased from the twenty started by LaLanne to over 35,000 fitness clubs with over 58 million fitness club members (Statistica 2015). Fitness programs evolved from "stay-at-home” exercising championed by LaLanne and other TV gurus such as Denise Austin and Jane Fonda to active involvement in fitness clubs where consumers of exercise can simultaneously develop or maintain their physique and show off the success of their efforts.

The preceding narrative describes fitness as a cultural development, one fostered by and mandated to support the survival of the civilization. As physical fitness became a desired cultural 
goal, society also evolved starting in the 1960's from a homogeneous culture to an expanding heterogeneous one where individual uniqueness gained greater acceptance. During this time, Kenneth Cooper, who established standards for cardiac rehabilitation, set forth early guidelines for aerobic fitness (Pantzar and Ruckenstein 2105, 100). In fitness, instead of wider societal goals such as national health, personal goals such as self-actualization became the primary motivation. This signals the inauguration of the self-constituting consumer in fitness (Karababa and Ger 2011); the active consumer who drops the structural divisions ascribed by the market and creates his or her own identity and meaning. In the context of personal training, creating one's own physical identity is the ultimate expression of the self-constituting consumer. Our bodies, posited as "the ultimate site for the production and display of self" represent a prime canvas for identity-development endeavors (Smith Maguire, 2008b, 59-60). Modern society places emphasis upon "becoming oneself” (Smith Maguire, 2002, 212) through various means. For example, Valtonen $(2013,198)$, who examines how consumers experience and re-negotiate what they deem ideal in different contexts, posits the body as being "constructed ... in and through social action.” The product of the training is the self, the physically ideal body created by the desires of the initiator. This ideal is a product of not only the postmodern philosophy of “doing your own thing," but a cultural history in the U.S. of the freedom of the individual of choosing his or her own life. Consistent with a postmodern condition, the fitness market has made available to consumers the resources to construct their own identity (Firat and Venkatesh 1995) from the personal gear used and worn to the rituals performed to achieve fitness. For instance, Pantzar and Ruckenstein (2015), posits that tracking devices, such as heart rate monitors, helps individuals to exercise control over their bodies by providing them with objective data thus allowing them to engage in self-coaching. Although such devices may 
“substitute for a human coach” (Matti Heikkilä as quoted in Pantzar and Ruckenstein 2015, 100), others may require the assistance of a second party, in order to achieve their fitness goals which raises other matters that must be considered. The following section delineates the research context and the methods.

\section{Method}

\section{Research context}

The pursuit of fitness through the expertise of a personal trainer (PT), which essentially constitutes an extended close-proximity service encounter, is a unique phenomenon in consumer culture. This is because the interactions of the client-trainer dyad heavily influence the dynamic goal formation and goal pursuit process. This “consumer-intensive co-production” as Fisher et al. (2009) coins it, focuses on the dynamic relationship that interconnects the consumer (the client) with the marketplace (the trainer) is consistent with consumers' actions, the marketplace, and cultural meanings considered under the purview of Consumer Culture Theory and entail goalconsumption sequences (Arnould and Thompson 2005).

Fitness goals are persistent goal pursuits due to their challenging nature and extended commitment. Thus, personal training is an ideal context in which to explore the question of "How do consumers and service providers in extended service encounters negotiate goal setting and goal pursuit?” Personal training aligns with Bagozzi and Dholakia’s (1999, 20) conception of "execution of instrumental acts" (i.e., exercise vigorously and consistently) to achieve a specific outcome. Based upon factors such as the fitness facility location, and the client's goals, personal training sessions normally range in length from thirty to ninety minutes. Extant research suggests that consumers engaging in personal training differ from those in other gym-context studies (Crossley 2004, 2005, 2006; Sassatelli 1999). In contrast to others, personal training 
clients (1) are often accustomed to the gym, (2) have made an active choice to transform their body and/or mindset, and (3) have made a conscious decision to engage a personal trainer to assist in their goal pursuit (Crossley 2004, 2005, 2006; Sassatelli 1999).

Personal training constitutes an example of “expert service work” which blurs the boundary between lower-level front-line occupations and higher-level knowledge work (George 2008). Expert service work, which is largely self-managed by the provider, entails the “performance of knowledgeable, customized, interactive labor” (George 2008, 115). Its nonroutine and unpredictable nature sets it apart from other front-line work (George, 2008). Due to its “ambiguous interaction roles” (115), expert service work is distinct from professional work which entails more clearly defined and regulated "content of the service and the role relations of the participants” (George 2008, 115). Thus expert service workers, such as PTs, exist in “an occupational middle ground” (George 2008, 115) because they aim to meet consumers’ individualized service demands while continuously establishing their authority, drawn from their professional credentials, often continually "negotiate[ing] professional and personal boundaries with their clients.” (George 2008, 123).

Personal trainers are considered cultural intermediaries (Smith Maguire 2008c) because they promote personalized fitness experiences and connect various aspects of the fitness industry to consumption. They stand at the intersection of production and consumption, "between economic and cultural agendas, knowledge and constraints” (Smith Maguire 2008c, 216), and utilize “their personal lives, bodies and tastes as crucial occupational resources” to establish legitimacy with consumers (Smith Maguire 2008c, 219). This is reflected in accounts of how PTs’ appearance and behavior affects consumers’ perceptions of the quality of their services. Such perceptions often necessitate an alignment between PTs' personal lives and occupation role 
because their own physique is an advertising medium for their fitness philosophy (Smith Maguire 2008a).

\section{Sampling, data collection, and analysis}

Data collection centered mostly on client-trainer pairs, as prior research has benefited from a dyadic perspective (Arnould and Price 1993; Bitner et al. 1994; Penaloza and Venkatesh 2006). The first author identified participants through purposive sampling (Glaser and Strauss 1967), with the clients primarily identified via referrals made by PTs or via author connections (see limitations). Personal trainer informants included in this research worked at a nationwide personal training company, a university health promotion for faculty and staff, or were selfemployed entrepreneurial-oriented trainers who either contracted with gym facilities or owned their own establishments. PT informants include ten males and four females ages 23-65 and the client informants include four males and thirteen females, ages 24-72. While data on the gender demographics of personal trainers is unavailable, we acknowledge that the percentage of female trainers in our sample (28.6 percent) is slightly lower than that reported in a recent study on the personal training industry (36 percent) (Melton et al. 2008). The diverse sample offers a nuanced understanding of consumers’ experiences of pursuing fitness and trainers’ perceptions of aiding this process (see Table 1 for informant profiles).

-- Insert Table 1 here $\quad$--

Data collection focused on gathering clients’ and PTs’ perspectives on the clients’ goal pursuit process including the management of expectations in negotiation and re-negotiation of their identity projects. Data collection occurred in two stages. Initially, the first author interviewed thirteen informants (seven trainer-client pairs with one trainer working with two clients interviewed) until saturation, typically established with eight informants in qualitative 
studies (McCracken 1988). Later in the research process, the same author interviewed 17 additional informants (10 clients and 7 trainers - for ten additional client-trainer dyads) to confirm some of the earlier research findings and to seek deeper understanding of the dyadic goal pursuit process.

The first set of individual, semi-structured interviews occurred over 13-months in two large Southwestern U.S. cities. The first author interviewed informants at gym facilities, in client or trainer offices, or the homes of the clients, ranged from thirty minutes to two hours. The researcher utilized active listening and probing techniques to aid the informants in expanding upon interesting topics (Spradley 1979). The second set of interviews took place in a small Southeastern university town in addition to one of the prior cities during a six-month span. The first author recorded and transcribed all interviews after each interaction. Where necessary, the first author followed up with participants to clarify information.

Additionally, the first author engaged in personal training at a U.S. national gym chain nine months prior to interview data collection. She trained twice a week with a personal trainer for a year. Over this time, she worked with two male and two female trainers. While she trained with the two males and one female for a few sessions each, she worked with the second female trainer for 11 months. Later, the first author joined a personal training studio, which focused on weight loss, owned by personal trainer, Josh, in a different city. At this facility, besides engaging in 20 personal training sessions, she participated in a detoxification program that included the use of an infrared sauna. The personal training experience sensitized the first author in understanding the process from a consumer's point of view. She also observed training sessions of select client-personal trainer dyads presented in Table 1. In all, the first author spent over 200 hours observing client-trainer interactions. The authors used the field notes to triangulate the 
interview data. The three authors analyzed the data individually through iterative readings of transcribed data using the hermeneutic interpretation of textual data method (Thompson 1997). Discrepancies in analysis were resolved through discussions and by re-interviewing some informants. Additionally, the first author followed up with four informants and three other noninformant gym clients for member checks. Below, we present the findings integrated with the extant literature. To protect informants’ privacy, we used pseudonyms.

\section{Findings}

In this section, we explicate what occurs in the interactions between the client and the trainer in their co-pursuit of the former's fitness goals. While one may contend that the goals are those of the client, there is nonetheless a partnership between the two in this extended service encounter. The nature of this partnership affects the success of the goal pursuit process. As noted in the introduction, we focus our attention on what occurs in the "Action initiation and control" stage as well as the gap between the "Formation of a goal intention" and "Action planning" stages of the Bagozzi and Dholakia (1999) framework. Additionally, we integrate the notion of intersubjectivity in the clients' goal pursuit efforts.

\section{Formation of a goal intention}

Consumers' conscious goals arise in three ways: 1) forced through rewards, coercion, or due to position occupied; 2) surfacing "automatically because of biological, emotional, moral, or ethical forces"; 3) resulting from the consumer's "reasoned reactions to either external stimuli . . , or internal stimuli” (Bagozzi and Dholakia 1999, 21). As Figure 1 indicates, clients pursue fitness goals for a variety reasons. Figure 1 represents a simplified visualization of the integration of clients' focal (Lose weight/ Tone up/ Flexibility - Bulk up/ Strength/ Balance continuum) and superordinate goals (Health/ Survival/Athletics - Aesthetics continuum). In instances where 
consumers disclosed multiple goals, we plotted the one that appeared to be most salient. While consumers' reasons for undertaking a goal can be as unique as the individuals pursuing the goals themselves, these goals often serve as a source of motivation in the goal pursuit process. As Figure 1 illustrates, Health/ Survival/Athletic reasons, such as a recommendation from their health care provider, motivate some consumers in their goals pursuits. While this is an external stimulus, internal stimuli, such as a desire to feel more energized, or a desire to improve their fitness abilities, motivate others to pursue goals due to Health/Survival/Athletic reasons. The following quote from Maria illustrates what drives a consumer on the Health/ Survival/Athletic end of the continuum.

“I am training to go off to war ... to hike 26 miles, run 6 miles with an 80 pound rucksack and do an intense obstacle course ... you have to carry a person on your back and run with them to safety. I am so far behind; I am so out of shape right now. I had to get additional support so that I can get the training I need. I need to be able to do all this in extreme heat; the weather over there is hot so the training I go through is physical endurance in heat. I have learned to push my body before, but it is getting harder to do. So, I got a personal trainer to help me, I just want to come back ...I just want to come back.”

While her impending deployment, a relatively unique superordinate goal, motivates Maria to pursue physical fitness, she shares the focal goals of losing excess fat and gaining muscle strength with other informants.

\section{-- Insert Figure 1 here --}

Additionally, the desire to be aesthetically pleasing as defined by cultural standards, also drive consumers in their goal pursuits. These consumers appear to have succumbed to culturally 
mediated messages that body maintenance and improvement are 'ideal pursuits' with the capacity to affect one’s individual identity (Smith Maguire 2001, 381). For these individuals, undertaking a personal training regimen may also be a way of investing in oneself (Smith Maguire 2002). For some clients, becoming fit and engaging in personal training is a means through which to stave off the aging process. Barbara, for example, shared "I wanted to try to get fitter before I got too old and it was too late...It was just to keep me motivated and maybe lose a few pounds and get a bit more toned before my birthday.” Some clients have multiple salient goals as indicated by Susanna:

"Right now ... my main goal is to be healthier and feel more attractive by losing about 40 pounds from my second pregnancy. But, in addition to losing the weight, I want to get in better cardio shape so that I can run and play with my children without getting exhausted. I also want to get a better posture and a stronger core. I have been able to lose weight with the help of a trainer before but it was hard work on my part as well and I am older now so I don’t feel as confident that I can do it as quickly but I am motivated to do my part.”

Besides the interactions between the trainer and the client, the pursuit of fitness through personal training comprise of several elements: the clients’ personal goals, their ideal self often constructed based on societal standards and cultural pressures, and the knowledge and experience of the trainer. These elements present competing ideals. The client, through introspection, engages in this process of intersubjectivity, or the co-creation of contexts and entities through the shared understanding of assumptions (Borgerson 2010). The phenomenological understanding of concepts and entities means that the interaction of many self-concepts affect ideas. In society, the cultural understanding of fitness is a constantly 
changing ideal from body types to specific physical characteristics. The goal-striving consumer may desire the culturally focused body idealized through celebrities, but when setting fitness goals, they face the intersubjective fitness goals dominated and developed by personal trainers. However, in defining the ideal body, the trainer focuses on the individual client and not on societal ideals. The trainer's purpose is to transform the client's goal into one that is consistent with his or her training philosophy and assessment of what is feasible for the client.

\section{Goal striving}

After the consumer determines a goal, he or she engages in goal striving. This entails planning how one would go about achieving the goal and includes a consideration of means of appraisal. Self-efficacy pertains to an individual's capacity to exercise control over the means needed to achieve his or her goal (Bandura, 1997). This notion of self-efficacy surfaced consistently in our findings. While all participants set the goal of becoming fitter, when appraising the available means, they identified a flaw or limitation in their ability to progress towards their fitness goal on their own. This is because the informants regarded themselves as being unable to execute an exercise plan on their own. For example, Pam's doctor recommended that she engage in weightbearing exercises to increase her bone density. Though she was a competitive athlete in her youth, she noted:

“The last time I tried working out on my own I ended up on crutches (laughter) I decided I better have someone guiding me through the exercises given that I don't want to screw up my knees again.”

In terms of the action-outcome expectancies - given the option of working out alone or with the help of a trainer who would provide a strict training regimen, the clients appraised that the latter is more likely to lead to goal attainment. Thus, clients are less likely to pursue a course 
of action that they do not see leading to goal achievement (Bagozzi and Dholakia 1999). While self-efficacy and action-outcome expectancies are primarily cognitive appraisals between the self and the required acts of achieving a goal, the affect towards means is the consumers' emotions regarding the goal pursuit activities (Bagozzi and Dholakia 1999). Though not explicitly stated, in most instances, the consumers were hopeful regarding personal training thus indicating positive affect towards this means.

In the current context, all three appraisals deal with the decision of whether to undertake a physical fitness regimen on one's own or to engage a personal trainer to aid in the process. For example, Tammy, a client, shared:

“I needed help ... I gained a lot of weight when I was pregnant. I really needed guidance and help. I couldn’t really do it on my own . . . I tried but I really didn’t understand the process of training and I didn’t have the scope of experience that I needed to exercise effectively ... So, I concentrated on what I really wanted to accomplish, instead of just doing a circuit and hoping that I would tone up and lose weight. Setting the goals with the trainer and meeting with someone on a regular basis, knowing how much cardio I would have to do in addition to the training.. . . I still rely on my trainer to give me that additional guidance that I need.”

While Tammy communicates her lack of self-efficacy about the exercise process clearly, her quote also implicitly communicates that she expects the actions prescribed by her trainer to lead to the desired outcome. Her narrative offers a sense of relief and compliance, and by extension, affect in the neutral to positive range.

Besides these appraisals, we posit that consumers who choose to engage a personal trainer undergo what we refer to as a moment of release. This process of relinquishing control 
occurs at multiple stages of goal striving, however it first arises with respect to appraisal of means and the decision to engage a personal trainer.

\section{Moment of release}

While some contend that consumers assume control of their bodies and destinies through exercise and healthy eating (Smith Maguire 2006), others argue that these actions signify a loss of control because, by pursuing societal and cultural ideals, consumers are akin to slaves under the tyranny of socially and culturally mediated discourses (Lloyd 1996). Similar to Smith Maguire (2006), our analysis indicates that informants pursue personal training as a means of assuming responsibility for their well-being. However, several clients noted an initial feeling of vulnerability with respect to acquiring the services of a personal trainer. As Susanna noted:

"I guess when you have a goal, and you know how to get there but for whatever reason you are not able to get there alone, you make the decision to work with a trainer. To me, it was like letting go of a bit of my control and accepting that I don't have control over that part of my life. Or complete control, at least, and that I needed outside help. Asking for help can be hard when you normally do things on your own.”

We find this relinquishment of control to be two-fold and will further elaborate throughout our findings. For most proficient adults who are accustomed to managing their lives independently, this requires letting go to a certain extent. As Tom, a personal trainer, shared: "Some of the clients that I work with have told me that it was hard to make the decision to get a trainer because they may be very successful in what they do in life and work in general as they are normally pretty good at most things that they do. But all of a sudden it is this part of their life that they can’t control, to meet their goals.” 


\section{Action planning}

Action planning entails the formation of a plan that includes specific details regarding the actions involved and "when, where, how and how long each of the actions necessary for goal attainment will be carried out” (Bagozzi and Dholakia 1999, 29). In this process, the trainer, while keeping the client's unique attributes in mind, designs a plan. For example, the trainers create an exercise plan for each client and each session, which the trainer later uses as a guide for instructing the client through various exercises (See Table 2 for an example of a four-session plan). However, while a trainer might develop a plan for a specific period (e.g. 3 months or 12 sessions), the client ultimately decides how long he or she will engage in the training process. This is especially so as there may be financial and other constraints that limit plan continuation.

Little was known about consumer plans at the time when Bagozzi and Dholakia’s (1999) framework was published. Since then, new research findings indicate that planning in goal pursuit may have a counterproductive effect on goal attainment depending on consumers’ beliefs and goal difficulty (Bayuk 2015; Beruchashvili and Moisio 2013). A consumer with a moderate to difficult fitness goal may benefit more from planning compared to a consumer with an easy goal (Bayuk 2015). As the informants of this study characterized their fitness goals as being challenging, our findings support the importance of the planning process in goal attainment. The personal training plans designed for clients includes exercise as subordinate goals that must be achieved to reach the consumers focal goal.

Literature on motivation and goal theory suggests that consumers who visualize themselves as reaching a goal are more likely to achieve that goal (de Mello and MacInnis 2007). We find that consumers who use visualization internally plan their goal-directed behavior. For instance, Maria, reported that visualizing with the guidance of her personal trainer helped her 
push her body past its prior limitations. During her workouts, she pictured war zones and, when in need of extra motivation, saw herself as being in the hot desert wearing full combat gear. To aid her physical and mental technique development, Josh, her trainer, had her exercise while wearing a 45-pound vest and sit in an infrared sauna before and after her workouts.

With respect to developing an effective plan, Bagozzi and Dholakia (1999) discuss three sub-dimensions: 1) completeness; 2) specificity; 3) and novelty. Completeness refers to whether each link in a course of action is specified. As consumers do not achieve their fitness goals easily or quickly, it is sometimes difficult to evaluate the completeness of a plan. Most trainers recommend clients to train with them at least two times a week. Some clients may schedule more sessions per week, others less depending on their availability of time and determination to meet their specified goal. Some trainers will offer suggestions or recommendations for workouts on days when sessions are not scheduled as well as dietary recommendations. Our informants shared their weekly plans that ranged from not very structured to unstructured. For example, Jessica, she met with her trainer three times a week in addition to playing soccer and doing cardio at her in-home gym using a elliptical or treadmill. Others, such as Rebecca and Liz, would only train with a trainer once or twice a week in addition to a doing a few yoga classes or playing golf once a week.

Specificity refers to having direction with regard to what activities need to be executed in different contexts. Recent research on goal specificity in the weight loss context suggests that consumers may be more successful with a high-low range of pounds to lose compared to a single number (e.g., 1-3 pounds vs. 2 pounds) (Scott and Nowlis 2013). Applying this to the current context, a more effective exercise goal may be to run 20-30 minutes after 4 weeks of training, or to bench press between 100-120 pounds after a specified period. Having high-low range goals 
may help in keeping the consumer motivated and encourage in re-engagement of the goal (continuation towards end goal).

Tom, for example, helps those clients who have yet to determine a goal with setting subgoals so that they can assess their improvement over time. In responding to the process of working towards a client's goal, he states:

"When we have an end goal, I break it into sub goals and try to obtain the subgoals first. I try not to worry about the big picture at first. Younger clients, like those in early 20s, typically don't have any end goals. For them, I make-up goals ... so that everyone sees results. It may not always be what they are interested in such as weight loss but it may be a huge increase in their overall activity, flexibility or overall energy level.”

Some clients discuss their exercise plans often and in depth with their trainers to be more engaged in the planning process, while others do not show as much engagement in the process. For example, Lynn would discuss her specific training challenges with her trainer in order to improve on her performance in different competitions. As she is very knowledgeable about fitness, she wants to understand her trainer's strategies and plans for her. She would review her plans together with her trainer so she knew the science behind the plans. Others like Daniel, who wants to regain the joy and motivation he had for exercise in his youth did not review the planned sessions in advance but arrive at the session and do his best in following the exercises.

Novelty pertains to how clients view cues and sequences in training practices, in essence if the client finds the training practices familiar and reliable. Some clients may prefer that the trainer changes the sessions often using different equipment and techniques such as kettle bells, TRX systems, and high intensity training while others may prefer more predictive exercise sessions with free weights and machines. For example, Maria notes: 
"His concept of training is different from everything else I have experienced ... I never imagined doing the rubber bands or how much you can gain strength doing that. ... The stuff he has me doing right now, I have never done before. His method of training, is more mental than it is physical. He gets your mind going first, because if you don’t get your mind there, your body won't get there.”

The personal trainers also consider the client's unique abilities and initial goals when engaging in action planning. For instance, Josh emphasizes the uniqueness of his clients and the infeasibility of a “one size fits all” approach:

"What if you are a track athlete? I have a person who wants to go into SWAT, I have a lady that is a captain in the military ... she is well ahead over 90 percent of the people who walk in my door...Genetics is different, inspiration is different, people's enthusiasm and then their dedication is different. You have to formulate the plan for the person ... It would be irresponsible to say that everyone should go through the same training.” This uniqueness influences plan novelty. For example, Jason, shares: "With clients who are confident in their goals and have a good fitness starting point, I know that they are up for it, from them I like to change things up a lot. I try different exercises with high intensity so that they feel that they get a great workout. However, with others, especially if they have injuries or other limitations, I have to be more cautious and stick to similar routines each week. However, with most clients, the first two-three weeks I am testing their abilities and commitment level by both changing things up to see how they respond to new exercises but also to see what they are capable of performing. It is just as much a learning period for me as it is for the client.” 
In getting to know the client, the trainer is better able to understand the client's situation, his or her motivators, and then develop a unique plan that suits the individual.

Despite the trainer formulating a plan, the implementation of said plan is very much at the client's discretion. The client may meet with the trainer and engage in the prescribed exercises however, plans often entail other things that the client must do outside of the training encounters. For example, some trainers may include independent workouts as well as offer dietary advice and failure to comply on these factors may negatively affect goal attainment. Consistent with the literature that posits compliance as an essential component of goal attainment (Bagozzi and Dholakia 1999; Dellande et al. 2004), Jessica shared that failure to comply with her trainer's exercise and nutritional guidelines posed challenges in reaching her goals. By engaging a trainer the consumer assumes to take control of their goal-directed behavior, however once the training process begins, he or she must release that control to the trainer.

One facet of this relinquishment of control entails intersubjectively as the client must negotiate with the Other, in this case the trainer, as to what constitutes his or her ideal self. Through this acceptance of the trainer's view as dominant, the client may perceive the fitness experience as a liberating experience instead of a limiting one. As the extended service encounter continues, through the sharing and rapport building process, the clients partially relinquish control when they negotiate and perhaps modify their initial goal with their trainers. This relinquishment continues further as trainers develop individualized training and lifestyle programs for their clients, which, if adhered to, increases the likelihood of goal attainment. In other words, while this process requires the clients to trust the trainers’ knowledge, goal attainment lies in what happens between the trainer suggesting a regimen and the client accepting it and putting it into practice. 
To increase the likelihood of a successful outcome, the trainer must consciously integrate the client's perspective and appropriately manage the client's perceived lack of control (Bateson 1985; Corrado 2002). Our analysis indicates that this is an opportunity for another 'moment of release' to occur in the personal training process. The client must trust the personal trainer and push past his or her preconceived limitations of attaining his or her fitness goal with the trainer's encouragement. While some of this trust-building may occur in the goal initiating phase where the client and PT share information and the client decides to enter into this partnership, the 'moment of release' occurs to the fullest extent in the subsequent stages where the client and personal trainer continue developing rapport. Though initially challenging, this release of control is welcomed by some consumers. Tammy, spoke of the relief it entailed:

"I am not sure that I am explaining the relief that I am getting of not being in control. Usually I am the one. . . in charge. I have to make decisions all day long, constantly. ... . You teach, you are in charge, you are responsible. You prep, you read, you lecture to, you plan activities. I am always in charge. At home I handle all the major decisions. I have kids ... so I trouble shoot with them. I do this one thing for me, when I am not in control, where someone else is guiding me. It is a relief to walk into that gym. I almost think of it as a sanctuary. That is my space, my time. I feel safe there. . . I feel comfortable, you know the drill. I can walk in and it is my cocoon for that 30-40 minutes. And when I leave, I feel very refreshed."

Tammy shares her content of not being in control and at the same time being comfortable in the training session thanks to her trainer's efforts. Although her trainer pushes her to the limit in every workout, the subdimensions of completeness, specificity and novelty in the action planning stage help her in reaching her goals. 
--Insert Table 2 here--

\section{Goal maintenance and protection of intention}

The last step in the goal striving process is to protect and maintain a goal, to revise a goal or to abandon a goal. These decisions are usually made jointly with the trainer after the trainer has had a proper chance to learn about the clients' commitment level (mental) and physical abilities and constraints. New identities can drive consumers from the present stage or what Levy-Navarro (2009) calls the "before" to the happily ever "after" stage. The so-called happily ever after stage is rarely experienced; once a particular identity goal has been reached, it is often impossible for the consumer to be "fully inhabiting and sustaining the coveted identity" (Parmentier and Fischer, 2011: 23). As Belk, Ger, and Askegaard (2003) note in their exploration of the “journeying away" from one identity to another, this means that consumers often establish new identity goals once they reach current goals. Though trainers must respect their clients' expectations and goals, they also have a responsibility to inform them when these expectations are unrealistic without destroying these individuals' willingness to undertake fitness activities. Informing a client that his or her aspirations are unrealistic is a sensitive matter, but, as one trainer stated, "we can’t all look like supermodels, we have to work with our unique build” (Fieldnotes, private PT facility). Therefore, the trainer may encourage a client to abandon a goal or revise a goal for better chances of goal attainment. Client uniqueness as well as the need for gentle reality checks were recurrent theme. Duane, a personal trainer, noted about managing his client's expectations:

“The conversation would begin like, I just need to lose weight or I don’t feel very good... I would be interested in improving my cardio capabilities or be able to walk certain distance without getting tired or I would like to lose 20 or 30 pounds. All of those 
expectations would come into it and then through the assessment process, I began to manage their expectations by educating them on the process. You can't go from 0 to 60 in 20 seconds, you know, it’s generally recommended to allow 16 weeks for improvement in one fitness category.”

In the personal trainer-client interaction, managing expectations plays an important role in goal maintenance and protection of goal intentions. Personal trainer, Ginny, noted:

"Expectations are the hardest thing to manage. People sometimes have very skewed selfimages and role models. I can’t look like you, and you can’t look like me, no matter how much we want to. We are different in height, bone structure, and genetic background. Every person has unique possibilities; a person can't lose 45 pounds in two months in a healthy way. So we have to look at what you can do realistically based on the individual's resources and make up. It is a team effort... It can be hard to tell someone that their goals aren't realistic and try to get them on the same page and still keep them motivated."

Being honest and direct with the client is a delicate process that the trainer must approach with care, giving allowance to the particular client's characteristics. When dealing with unrealistic expectations, several trainers initially focused on the individual's strengths before discussing whether the client could meet his or her fitness goals within the specified timeframe. While these trainers were honest with their clients, they nonetheless attempted to soften their difficult messages to maintain the clients hope, foster their aspirations in a realistic manner, and not demotivate them from embarking upon healthy life changes. Ginny's quote sheds light on this: "It is important for me to be supportive at all times and try to be there for the client no matter what. I take the time needed for them to talk to me about things. I tell them that 
they are doing well and give them encouraging feedback and comments. I have heard them say that they like coming to me because I am the only one in their life that says that they are good at something.”

In addition, Tammy speaks of when her trainer gave her difficult feedback:

"I started in the spring of 2013 but it was right around Thanksgiving the same year and he said to me: "You are going to have to make a decision, you need to lose weight and until you do, I can't do any more for you.” That was a tough thing for him to say to me, it was a tough thing for me to hear but I lost 7 pounds between Thanksgiving and when I came back from the holiday break in mid-January... I said to him - I am ready to go.” Past research supports the importance of consistency and congruence in goal alignment (Huffman et al, 2000). The aforementioned planning stage assists this process. As personal trainer, Lenny, noted, “The road to success is to have consistency - a set plan of action, and then to follow it rigorously.” Another, Josh, stated:

"The hardest part of the job is when clients are not dedicated enough to come on a consistent basis. I want to see each and every one of my clients become successful but if they start skipping their work outs or are not putting in enough effort into the sessions and outside of here they simply won't reach them.”

Consumers who are successful in integrating fitness into their lives through consistent gym attendance establish a routine or ritual (Crossley 2004, 2006). Personal trainers holding clients accountable for their fitness-related decisions assist in forming routines and rituals. McCracken (1986, 78) defines a ritual as "a kind of social action devoted to the manipulation of cultural meaning for collective and individual communication and categorization. Ritual is an opportunity to affirm, evoke, assign, or revise the conventional symbols and meaning of the 
cultural order.” This consistency and the establishment of rituals, which trainers repeatedly indicate is the most important factor in goal attainment, is the facet of training that clients found to be most challenging. They reported difficulties in making time for fitness in their hectic lives and spoke of occasionally manufacturing excuses to avoid working out (Field notes, Gym facility). However, the sense of accountability to their trainer and their respect for their time prompted these individuals to attend PT sessions even when they felt unmotivated. As Jessica notes, "I would never cancel on him unless I absolutely had to, and if I did I would have to be seriously ill, or stuck in traffic or something.” To this end, some trainers had a 24-hour cancellation policy to encourage consistent attendance and indicate to clients that their time is valuable.

Rituals extend beyond consistent attendance of personal training sessions to include other healthy behaviors. For example, Peter, who regarded frequent eating as a routine necessary to reach his goals, noted:

“I didn’t even know that you had to eat six meals a day. In my work you just eat when you have a chance and in college you eat when you have a chance because you are always traveling or in class, but in body building it is routine. It becomes a routine, it becomes a must for you to lose the body fat that you need to expose the muscle, to give you the cut.”

Consistency and the establishment of rituals with the support of the personal trainer is important in the client achieving goal alignment and ultimately goal attainment.

Our findings show that clients maintaining their goals are more apt to adhere to advice of trainers who enact their own advice because trainers' self-compliance add veracity to their claims and persuade clients that the trainers' regimen, though challenging, holds merit. The lack 
of authenticity and genuine interest on part of the service provider negatively affects service relationships (Price et al. 1995a). For example, our analysis indicates that, as the service encounter progresses the trainer's own fitness-related behaviors influence the client as either a motivating or demotivating force. For example, Jessica notes of her trainer:

“He lectured about nutrition, but he said “I don’t do this right now, (laughing while petting his stomach), but I am planning to start soon...” How motivating is that? It felt like he was too good for the program he recommended. Here I am supposed to follow this strict nutritional plan, but my trainer can’t even follow it...talk about hypocritical.” Clients who perceive their trainers' behavior as being unethical or unprofessional may leave the service prematurely or engage different trainers (Melton et al. 2011). Trainers must be cognizant of clients' perceptions and lead by example to manage their expectations and influence the degree of effort they expend in bodily transformation efforts. A gap in understanding between the trainer and client could lead to clients' perception of service failure. It is critical for personal trainers to aim for goal congruency with their clients and to keep them informed by sharing the reasoning behind certain decisions in the process of fitness goal pursuit. Unless clients experience success in that they observe a decrease in the gap between their current physical state and their desired end state, consumers are unlikely to continue investing in personal training services, and are likely to either exit the service or search for a new trainer (Brown and Swartz 1989). We note that clients are less likely to abandon their goal pursuits if fitness is ritualized. It is important to note that attained goals of bodily transformation obtained through personal training are not static and clients must continue to engage in their fitness activities to preserve what they have gained. We contrast our findings with consumers who are capable of self-coaching using heart rate monitors. Panztar and Ruckenstein $(2015,103)$, for example 
found that consumers who used self-tracking devices to improve their health and exercise abilities developed a renewed relationship with their hearts in a positive manner; "hearts and their beating starts to matter more.” Thus, clients who see similar positive bodily transformations from personal training may start their viewing their body in a more positive light and the body becomes more valuable to the consumers once they start seeing its possibilities.

\section{Discussion}

Previous research on persistent goal pursuit (e.g. Fischer et al. 2007) discusses how consumers in the Assisted Reproductive Technologies (ART) industry respond to healthcare interventions in their pursuit of parenthood. In the ART context, the consumer's role in ensuring goal attainment through following the service provider's plans (i.e. treatment methods) is somewhat limited in that, besides engaging in persistent efforts, success is largely dependent on her biological factors. Thus, external factors such as the environment (Gollwitzer 1996), in this case that of the body, controls goal attainment. We therefore emphasize that consumers' participation towards goal attainment and their ability to achieve their goal is constrained by both cognitive and physical abilities. In the present study, we offer additional insight on persistent goal pursuit where the consumers' bodily actions, with the guidance of a personal trainer, can result in progress towards goal attainment.

Placing oneself in the care of a personal trainer is a highly emotional and complex process. Engaging a personal trainer means that, on some level, the consumer 'outsources' his or her physical and, to a certain extent, mental well-being to an external service provider, an expert. The consumer experiences some vulnerability in the formation of goal intention stage when he or she relinquishes control. The “moment of release,” which extends research on consumers' bodily self-control through exercise (Crossley 2004; Sassatelli 1999), and other transformative services 
and role transitions such as plastic surgery (Askegaard et al. 2002; Schouten 1991), extreme sports (Celsi et al. 1993; Arnould and Price 1993) and wedding dress shopping (Corrado 2002), is an important factor in the extended goal pursuit process. For example, Maria described it as "being naked with the trainer ... to bare your soul so the trainer can understand what is going on in your life.” A client, in sharing his or her goals and expectations regarding their ideal self with the trainer, releases some control over the situation at hand to the trainer. We note that Fisher et al. $(2007,436)$ describe a moment of "letting go" where the consumer realizes that neither she nor the medical professional can ensure success in the pursuit for parenthood, only a "higher power" can. This is different from the moment of release described in this research as relinquishing control; the client places him or herself in the hands of the trainer.

The goal striving stages of appraisal of means and action planning both entail intersubjective interactions. For instance, a consumer may come to personal training wanting to get more toned. In terms of what this means, one answer may be that the consumer wants more defined muscles described by culturally mediated messages. By using phrases such as "get more toned," "bulk up”, and "slim down”, the personal pursuit of fitness is repackaged into phrases that are related to the current cultural understanding of what constitutes fitness. For example, when Pam's doctor informed her of her decreased bone density, he wanted her to do weight bearing exercises. Translating the goals into actions, however, requires the participants to accept the subjective language borrowed from cultural constructs concerning fitness. Yet the acceptance of these intersubjective definitions does not empower the clients with the ability to translate them to actions. As these action phrases are borrowed from accepted definitions of fitness-defined work, the experience and knowledge to translate these words to actions is not encapsulated in the concepts. It is at this junction where the client experiences his or her moment of release and 
invests in a personal trainer to augment this translation. Thus, in the appraisal phase the client solicits the input of a personal trainer to translate his or her fitness desire, or recommendation from the physician into goal pursuit actions, which essentially constitutes a plan for attaining the goal. Similar to Pantzar and Ruckenstein’s $(2015,101)$ findings on self-tracking devices (such as heart rate monitors) that "breaks down the body into culturally legible images such as fitness graphs," the exercise plans and noted progress help clients in their understanding of fitness including the fact that goal attainment is a lengthy process. In accepting the intersubjectively defined actions as conduits to fitness, the clients must accept the input of actors with the knowledge and skills to translate the action-phrases to fitness-related work. Susanna's multifaceted goal of getting healthier by losing excess weight was translated to include get in better cardio shape, and develop a better posture, and a stronger core. In order to exercise with the objective of obtaining a stronger core, the client needs to know that it is important to work both abdominal and back muscles to balance the core and that only focusing on one set of muscles, for instance the abdominals can lead to injury.

In considering intersubjectivity, the dyadic relationship between the trainer and client requires not just negotiation but general acceptance of the trainer's fitness concepts. Fitness may be the ultimate expression of ego. The desire to achieve physical perfection rests in the consumer's vision of perfection. The trainer's vision based upon their experiences may be entirely different. Depending on multiple health factors including age, physical abilities, and personal desire, the trainer may consider the consumer's desire impossible to achieve. In the goal maintenance and protection of intention stage, the trainer may utilize referent and positional power to convince the consumer to accept a redefined goal. The consumers' desire significantly 
diminishes and success becomes problematic if the consumer does not or cannot accept this vision.

It is here where trainers should consider Borgerson’s (2010) understanding of witnessing and its role in understanding human behavior. The role of witnessing in this context is to limit both dominance and subordination in intersubjectively defining fitness between trainer and client. Witnessing is both subjectivity and the subject position; a trainer can understand both roles and consider both the external person and the internal person; the story of their lives and their deepest desires. While many would see the trainer as being dominant in the relationship with the client, in the spirit of true co-creation, the trainer must consider the Other in constructing an interdependent and cohesive vision for the consumer, one where the clients is not only physically fit, but emotionally and spiritually healthy/capable as well.

The extant consumer research within the personal training context primarily focuses on the perspective of one party in the encounter and the success or failure of the service encounter. This is the final, goal attainment or failure stage of Bagozzi and Dholakia's (1999) goal pursuit framework. The current research contributes to this literature on two levels. First, we study the personal training encounter from the perspectives of both the client and trainer. Second, we extend Bagozzi and Dholakia’s (1999) cognitive goal pursuit framework by contributing the moment of release that occurs in extended goal pursuits involving a service provider. Third, we integrate the idea of the consumer's cognitions, the notion of intersubjectivity, into the goal setting and pursuit process. This entails the consumer conversing with multiple understandings of fitness (i.e. cultural ideals posited by society, various understandings held by the self, and the perspective of the service provider) and integrating these to determine more specific goal objectives, and expectations. In the process of consumers sharing and negotiating their goals and 
outcome expectations with their trainers, their conceptualizations of the ideal self changes partly due to the trainers' input. While the trainers' input is important throughout the goal striving process, it is especially important in the appraisal of means and goal maintenance stages. It is in these stages that the trainer manages the clients' expectations and provides feedback including the feasibility of his or her goals. In such instances, when a client accepts that her initial goal may be unrealistic, she may decide to pursue an achievable goal with the help of the trainer. Though based in the personal training context, the findings of this research would apply in any close proximity extended service encounter, which calls up on the client to rely on the service provider’s expertise. Our theoretical contributions can assist service providers in methodically improving their service offerings. Personal trainers, cognizant of the complexity within this situation, empower their clients by integrating their perspectives and asking them to make certain decisions in these service encounters. This research could assist scholars in examining the microprocesses entailed in goal pursuit.

Future research could explore the release of control, as it appears to play an important role in clients' commitment to training with a personal trainer. For many, placing oneself in the hands of another is a challenge and it may be more of a challenge in personal training context where means of exhibiting trainer expertise are varied and thus unclear. For example, Celsi et al. (1993) found that experienced skydivers felt they were in control more than those with less experience. However, while the consumer bases his or her trust on training, previous jumps, and accident statistics, the consumer nonetheless relinquishes some control to the instructor, nature, and the equipment. We find that the client's moment of release is necessary for the process of buying in and adhering to the personal trainer's regimen and for goal attainment. However, various factors including clients' personalities, their perceptions of the trainer, and characteristics 
of the relationship between the dyad influences the goal attainment (Fischer et al. 2009). As such, since this is an important part of expert-services contexts, it bears further exploration to tailor services that meet consumers’ unique needs and helps them in goal attainment.

Being a qualitative study, our research is rich with contextual data but is limited in certain ways. However, Thompson and Hirshman's (1998: 441) statement, "the sampling frame is both a limitation and an opportunity” certainly applies to this study. In terms of a limitation, given that the researchers developed the client sample largely through referrals by trainers or through author connections, it is likely that these clients were those who followed the trainers' guidelines. As our intent was to understand the process through fitness goal pursuit, one may argue that this positively biased sample was ideal for elucidating the process. While the presence of largely female clients and male trainers can be viewed as a limitation, this can also be an avenue for future research on female trainers and male clients. Although the methods of in-depth interviews and participant observation limit the generalizability "by the spectrum of environments sampled" (Price et al. 1995b, 50), the findings are applicable to other services that involve co-production of value in the service encounter and outcome, such as weight loss centers, plastic surgery, and financial investment or insurance services, where a dialectic goal negotiation process takes place.

\section{Conclusion}

This research provides an understanding of what occurs in goal pursuits that involve the aid of an expert. The prevailing cultural standards influence us in all aspects of our lives including the goals we establish for ourselves. Often, many goal pursuits, such as that for beauty, health, or fitness, are multi-faceted in that they encompass multiple qualities. Thus, an individual must assess culturally posited standards in relation to his her own ideals and hopes in determining a goal. 
Some individuals choose to engage experts to aid them in the goal pursuit process for two reasons. First, they recognize that they are unable to make satisfactory progress towards the desired goals without aid. Often, consumers may feel inadequate, even lost, in translating their goals into action. Second, they acknowledge that experts are authorities on the topics pertaining to the particular goals in question. In essence, engaging an expert, entails the consumer giving up some control of his or her personal situation to another party. This, to some extent, is based upon to what extent the consumer trusts or has confidence in the personal trainer. Thus, efforts towards developing consumers' trust is likely to positively influence the client giving up control and compliance. Once the initial buy-in from the client, the goal pursuit process entails multiple other opportunities where the consumer has to decide whether or not to relinquish a part of his or her control, autonomy, to the trainer.

One such opportunity entails the potential modification of the consumer's initial goal, his or her initial aspiration. As noted earlier, a consumer develops a goal from considering the interplay between cultural standards and his or her own ideals. The cultural understanding of fitness entails multiple qualities. Thus, the expert, in this case the trainer, influences the consumer's translation of cultural standards or ideals pertaining to fitness. As noted, consumers have some idea of to what they aspire which is often based on their own preferences and cultural standards. However, an expert, whether it be a plastic surgeon, a personal trainer, or a voice coach, will modify the consumer's vision to the expert's vision of what is possible based on the consumer's capabilities. Thus the expert's input redefines and clarifies the consumer's vision and goal, and sometimes pushes the consumer towards the unknown previously unimagined possibilities or might constrain the consumer’s vision. This may lead to initial goals being 
redesigned, redefined, modified, or abandoned. This, the engagement of experts,' influences consumers in their goal striving pursuit through the notion of intersubjectivity. 
Table 1. Profiles of client-trainer dyads

\begin{tabular}{|c|c|c|c|c|c|}
\hline Client & $\begin{array}{c}\text { Time } \\
\text { with } \\
\text { Trainer }\end{array}$ & $\begin{array}{l}\text { Sessions } \\
\text { per } \\
\text { Week }\end{array}$ & $\begin{array}{c}\text { Number of Previous } \\
\text { Trainers }\end{array}$ & Trainer & $\begin{array}{l}\text { Servicescape } \\
\text { (Location) }\end{array}$ \\
\hline $\begin{array}{l}\text { Justin, 33, Caucasian } \\
\text { Accountant }\end{array}$ & 3 months & $2-3$ & None & $\begin{array}{l}\text { Matt, 31, Caucasian } \\
\text { PT/ Former Fitness/Body } \\
\text { Builder }\end{array}$ & $\begin{array}{l}\text { Contracted at } \\
\text { national gym } \\
\text { chain }\end{array}$ \\
\hline $\begin{array}{l}\text { Rebecca, 55, } \\
\text { Caucasian } \\
\text { Nurse Technician }\end{array}$ & $\begin{array}{l}\text { over } 2 \\
\text { years }\end{array}$ & 1 & $\begin{array}{l}2 \text { male PTs several years } \\
\text { ago }\end{array}$ & $\begin{array}{l}\text { Lenny, 65, Hispanic } \\
\text { PT/ Olympic Weight Lifting } \\
\text { Coach/retired Police Officer }\end{array}$ & Own facility \\
\hline $\begin{array}{l}\text { Liz, 53, Caucasian } \\
\text { Homemaker }\end{array}$ & 2 years & 1 & None & $\begin{array}{l}\text { Betty, 51, Caucasian } \\
\text { PT/ Nutritionist }\end{array}$ & $\begin{array}{l}\text { Contracted at a } \\
\text { local gym and } \\
\text { in-home at } \\
\text { clients houses }\end{array}$ \\
\hline $\begin{array}{l}\text { Peter, 29, Hispanic } \\
\text { Retail Manager }\end{array}$ & 5 months & $2-3$ & None & $\begin{array}{l}\text { Jason, 30, Caucasian } \\
\text { PT/Firefighter }\end{array}$ & $\begin{array}{l}\text { Contracted at a } \\
\text { local gym }\end{array}$ \\
\hline $\begin{array}{l}\text { Lynn, 27, Caucasian } \\
\text { Project Manager }\end{array}$ & 1.5 years & 2 & $\begin{array}{l}\text { Sporadic one-on-one } \\
\text { coaching in swimming/ } \\
\text { running before starting } \\
\text { PT }\end{array}$ & $\begin{array}{l}\text { Ginny, 36, Caucasian, } \\
\text { PT/Group Fitness Instructor }\end{array}$ & $\begin{array}{l}\text { Contracted at a } \\
\text { local gym }\end{array}$ \\
\hline $\begin{array}{l}\text { Jessica, 38, } \\
\text { Caucasian, Realtor }\end{array}$ & 2.5 years & $3-5$ & $\begin{array}{l}1 \text { male PT several years } \\
\text { ago }\end{array}$ & $\begin{array}{l}\text { Josh, 31, Hispanic } \\
\text { PT/Nutritionist }\end{array}$ & Own facility \\
\hline $\begin{array}{l}\text { Maria, 36, Hispanic } \\
\text { Soldier }\end{array}$ & 6 weeks & $5-7$ & $\begin{array}{l}2 \text { male PTs several years } \\
\text { ago }\end{array}$ & $\begin{array}{l}\text { Josh, 31, Hispanic } \\
\text { PT/Nutritionist }\end{array}$ & Own facility \\
\hline $\begin{array}{l}\text { Pam, 57, Caucasian, } \\
\text { Director, College } \\
\text { preparatory program }\end{array}$ & 1.5 years & 2 & $\begin{array}{l}1 \text { male PT two years ago, } \\
\text { several personal coaches } \\
\text { while figure skating }\end{array}$ & $\begin{array}{l}\text { Tom, 23, Caucasian } \\
\text { PT/ Graduate Student in } \\
\text { Exercise Science }\end{array}$ & $\begin{array}{l}\text { Contracted at a } \\
\text { University gym } \\
\text { for faculty/ staff }\end{array}$ \\
\hline $\begin{array}{l}\text { Tammy, 66, } \\
\text { Caucasian, Librarian }\end{array}$ & 3.5 years & $2-3$ & $\begin{array}{l}3 \text { male PTs during the } \\
\text { last } 3.5 \text { years, } 1 \text { female } \\
\text { PT twenty years ago }\end{array}$ & $\begin{array}{l}\text { Trevor*, 25, Caucasian, } \\
\text { Personal Trainer, student in } \\
\text { Exercise Science, Kinesiology }\end{array}$ & $\begin{array}{l}\text { Contracted at a } \\
\text { University gym } \\
\text { for faculty/ staff }\end{array}$ \\
\hline $\begin{array}{l}\text { Susanna, 40, } \\
\text { Caucasian, Professor }\end{array}$ & 8 years & $2-3$ & $\begin{array}{l}2 \text { female PTs eight years } \\
\text { ago, 5-6 male trainers } \\
\text { the last 5-6 years }\end{array}$ & $\begin{array}{l}\text { Kenneth, 22, Caucasian, PT } \\
\text { Exercise Science }\end{array}$ & $\begin{array}{l}\text { Contracted at } \\
\text { University gym } \\
\text { for faculty/ staff }\end{array}$ \\
\hline $\begin{array}{l}\text { Daniel, } 42 \text {, } \\
\text { Caucasian, Professor }\end{array}$ & 5 years & 2 & $\begin{array}{l}3 \text { male PTs during the } \\
\text { last five years }\end{array}$ & $\begin{array}{l}\text { Tom, 23, Caucasian } \\
\text { PT/ Graduate Student in } \\
\text { Exercise Science }\end{array}$ & $\begin{array}{l}\text { Contracted at a } \\
\text { University gym } \\
\text { for faculty/ staff }\end{array}$ \\
\hline $\begin{array}{l}\text { Mike, 26, Caucasian, } \\
\text { Account Manager }\end{array}$ & $5+$ years & $5-6$ & $\begin{array}{l}\text { Multiple team coaches } \\
\text { for football and } 3 \\
\text { personal coaches/ } \\
\text { trainers }\end{array}$ & $\begin{array}{l}\text { Team of three personal } \\
\text { coaches* }\end{array}$ & $\begin{array}{l}\text { University } \\
\text { Athletics }\end{array}$ \\
\hline $\begin{array}{l}\text { Amy, 72, African } \\
\text { American, Retired }\end{array}$ & 3 years & 3 & None & $\begin{array}{l}\text { Duane, } 50 \text { Caucasian, PT/ } \\
\text { Nutritionist }\end{array}$ & Own facility \\
\hline $\begin{array}{l}\text { Barbara, } 40, \\
\text { Caucasian, } \\
\text { Motivational Speaker }\end{array}$ & 6 months & $3-5$ & $\begin{array}{l}2 \text { male PTs several years } \\
\text { ago }\end{array}$ & $\begin{array}{l}\text { Stephanie, 23, Caucasian, PT/ } \\
\text { Dancer (aspiring police } \\
\text { officer) }\end{array}$ & $\begin{array}{l}\text { Contracted at } \\
\text { national gym } \\
\text { chain }\end{array}$ \\
\hline $\begin{array}{l}\text { Ana, 24, Caucasian, } \\
\text { Graduate Student }\end{array}$ & 2 months & $2-3$ & $\begin{array}{l}\text { Numerous swim coaches } \\
\text { for } 15+\text { years }\end{array}$ & $\begin{array}{l}\text { Bobby, 25, African American, } \\
\text { PT, Bartender }\end{array}$ & $\begin{array}{l}\text { Contracted at } \\
\text { national gym } \\
\text { chain }\end{array}$ \\
\hline $\begin{array}{l}\text { Laura 53, Caucasian, } \\
\text { Career coach }\end{array}$ & $1+$ years & 1 & $\begin{array}{l}1 \text { additional coach } \\
\text { (recently hired a cycling } \\
\text { coach)* }\end{array}$ & $\begin{array}{l}\text { Michelle, 40, Caucasian, PT/ } \\
\text { Running coach, Group fitness } \\
\text { instructor/ Nutritionist }\end{array}$ & $\begin{array}{l}\text { Contracted at } \\
\text { National gym } \\
\text { and private } \\
\text { lessons }\end{array}$ \\
\hline
\end{tabular}




\begin{tabular}{|l|l|l|l|l|l|}
\hline $\begin{array}{l}\text { Theresa, 28, } \\
\text { Hispanic, Investment } \\
\text { banker }\end{array}$ & 2 months & $2-3$ & None & $\begin{array}{l}\text { David 32, Caucasian, Personal } \\
\text { Trainer, Swimming coach }\end{array}$ & $\begin{array}{l}\text { Contracted at } \\
\text { local gym and } \\
\text { private lessons }\end{array}$ \\
\hline
\end{tabular}

*not interviewed for this study 
Table 2. Sample exercise plan: week 4 and 5 in a three month period.

\begin{tabular}{|c|c|c|c|c|}
\hline Client name & $\begin{array}{l}\text { Week 4, } \\
\text { Session } 1\end{array}$ & $\begin{array}{l}\text { Week 4, } \\
\text { Session } 2\end{array}$ & $\begin{array}{l}\text { Week 5, } \\
\text { Session } 1\end{array}$ & $\begin{array}{l}\text { Week 5, } \\
\text { Session } 2\end{array}$ \\
\hline $\begin{array}{l}10-20 \text { min } \\
\text { warm-up on } \\
\text { either } \\
\text { elliptical, } \\
\text { bike, or } \\
\text { treadmill on } \\
\text { your own. }\end{array}$ & $\begin{array}{l}\text { - row interval.. } \\
\text { 2min warm-up, } \\
3 \text { x 30sec bursts } \\
\text { (only do this } \\
\text { once) } \\
\text { - TRX back } \\
\text { squat x } 12 \\
\text { - 21's with } \\
\text { 30lbs... calf } \\
\text { raises } \\
\text { - Barbell } \\
\text { deadlift, at } 45 \text {-- } \\
>55 \text {--> 65lbs x } \\
10 \\
\text { - supermans for } \\
1 \text { min } \\
\text { - Kettle bell } \\
\text { romanian dead } \\
\text { lift w/ 25lbs x } 10 \\
\text {... repeat } \\
\text { exercises 2-3 } \\
\text { times except for } \\
\text { row intervals. }\end{array}$ & $\begin{array}{l}\text { - warm-up: row } \\
\text { interval... 2min } \\
\text { easy, 2x 30sec } \\
\text { bursts } \\
\text { - Lat pulls x } 15 \\
\text { at } 55 \text { and 60lbs } \\
\text { - chest press } \\
\text { machine x } 15 \text { at } \\
50 \text { and } 55 \\
\text { - In and out } \\
\text { dumbbell } \\
\text { shoulder raises } \\
\text { w/ 8lbs x } 16 \\
\text { - Dumbell curl x } \\
15 \text { with } 12 \text { lbs } \\
\text { - tricep push } \\
\text { down x } 15 \text { with } \\
25 \text { lbs } \\
\text { - seated row x } 15 \\
\text { with 60/ 65lbs } \\
\text { - 50sec plank } \\
\text {.. repeat } \\
\text { everything but } \\
\text { the war-up row } \\
\text { intervals 2-3 } \\
\text { times. }\end{array}$ & $\begin{array}{l}\text { - row interval.. } \\
\text { 2min warm-up, } 3 \\
\text { x 30sec bursts } \\
\text { (only do this } \\
\text { once) } \\
\text { - X-press squats } \\
\text { with 10lbs x } 15 \\
\text { - wall sit curls } \\
\text { with 12lb x10 } \\
\text { - tricep kick back } \\
\text { with 5lb x10 } \\
\text { - superman/ } \\
\text { banana for 1min } \\
\text { - russian twist w/ } \\
\text { feet down x } 30 \\
\text { - in and outs x } 20 \\
\text {... repeat } \\
\text { everything 2-3 } \\
\text { times }\end{array}$ & $\begin{array}{l}\text { - row interval.. } \\
2 \text { min warm-up, } \\
3 \text { x 30sec bursts } \\
\text { (only do this } \\
\text { once) } \\
\text { - } 30 \text { kettle bell } \\
\text { swings w/ 20lb } \\
\text { ball } \\
\text { - TRX row x } 12 \\
\text { - TRX press x } \\
12 \\
\text { - 30sec ski } \\
\text { jumps } \\
\text { - walking } \\
\text { planks for 90sec } \\
\text { - cross chops } \\
\text { with 8lb ball x } \\
10 \text { each side } \\
\ldots \text { repeat } \\
\text { everything 2-3 } \\
\text { times }\end{array}$ \\
\hline $\begin{array}{l}\text { Twice a week } \\
\text { (on your } \\
\text { own) }\end{array}$ & \multicolumn{4}{|c|}{30 -60 minutes of cardio (brisk walk, jogging/ run/ hike) } \\
\hline $\begin{array}{l}\text { Once a week } \\
\text { (on your } \\
\text { own) }\end{array}$ & \multicolumn{4}{|c|}{$\begin{array}{l}\text { Ab/ back workout: (planks, - front/ side-, crunch -front/obliques-, sit-ups, } \\
\text { Russian twists, hip raises, leg raises, etc) }\end{array}$} \\
\hline
\end{tabular}


Figure 1. Visual continua of clients' formation of goal intentions

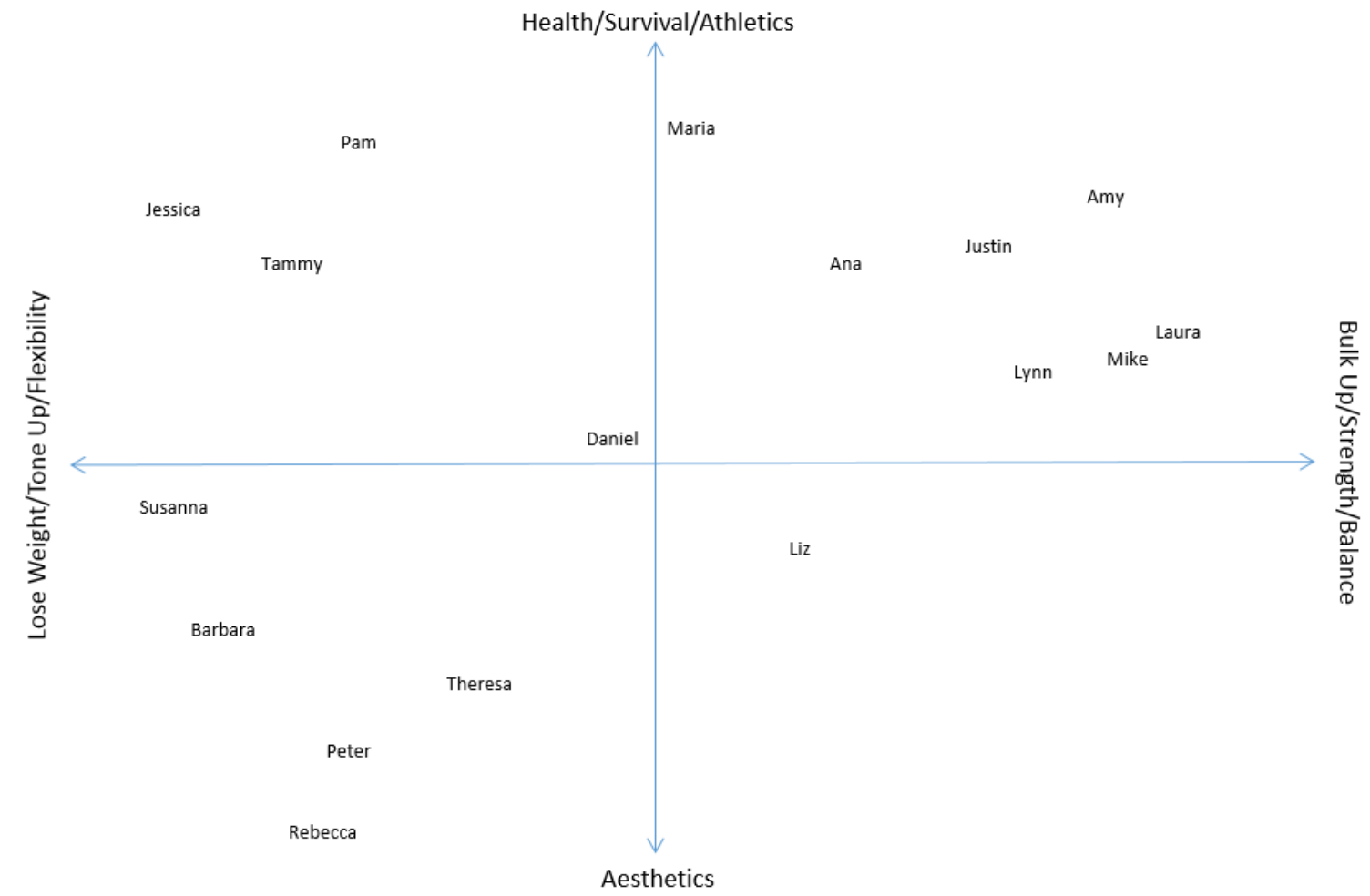

Vertical Continuum: Superordinate goals indicate why consumers strive for their focal goals. Horizontal Continuum: Focal goals indicate what specifically consumers strive for. 


\section{References}

Arnould, Eric, J., and Linda L. Price. 1993. "River Magic: Extraordinary Experience and the Extended Service Encounter.” Journal of Consumer Research 20 (June): 24-44.

Arnould, Eric J., and Craig J. Thompson. 2005. "Consumer Culture Theory (CCT): Twenty Years of Research.” Journal of Consumer Research 31 (March): 868-82.

Askegaard, Soren, Martine C. Gertsen and Roy Langer. 2002. "The Body Consumed: Reflexivity and Cosmetic Surgery.” Psychology and Marketing 19 (10): 793-812.

Bagozzi, Richard P. 1992. “The Self-regulation of Attitudes, Intentions, and Behavior.” Social Psychology Quarterly 55 (2); 178-204.

Bagozzi, Richard P. and Utpal Dholakia. 1999. "Goal Setting and Goal Striving in Consumer Behavior.” Journal of Marketing 63 (Special Issue): 19-32.

Bandura, Albert. 1997. Self-efficacy: The Exercise of Control. New York: W. H. Freeman.

Barrow, Harold M. and Janie P. Brown. 1988. Man and Movement: Principles of Physical Education (4th ed.). Philadelphia, PA: Lea and Febiger.

Bateson, John E.G. 1985. “Perceived Control and the Service Encounter.” In The Service Encounter: Managing Employee/Customer Interaction in Services Businesses, edited by John A. Czepiel, Michael R. Solomon, and Carol F. Surprenant, , 67-82. Lexington, MA: Lexington Books.

Bayuk, Julia. 2015. "Should I Plan? Planning Effects on Perceived Effort and Motivation in Goal Pursuit.” Journal of Consumer Behaviour 14 (August): 344-352.

Belk, Russell W., Guliz Ger, and Soren Askegaard. 2003. "The Fire of Desire: A Multi-sited Inquiry into Consumer Passion. Journal of Consumer Research 30 (3): 326-51.

Benjamin, Jessica. 2004. "Beyond Doer and Done To: An Intersubjective View of Thirdness." The Psychoanalytic Quarterly 73 (1): 5-46.

Beruchashvili, Mariam and Risto Moisio. 2013. "Is Planning an Aid or an Obstacle? Examining the Role of Consumers' Lay Theories in Weight Loss. Journal of Consumer Affairs 37 (3): 404431.

Bitner, Mary J., Bernard H. Booms, and Lois A. Mohr. 1994. "Critical Service Encounters: The Employee's Viewpoint.” Journal of Marketing 58: 95-106.

Bloch, Peter H. and Marsha L. Richins. 1992. "You Look "Mahvelous": The Pursuit of Beauty and the Marketing Concept." Psychology and Marketing 9 (January): 3-15. 
Borgerson, Janet. 2010. "Witnessing and Organization: Existential Phenomenological Reflections on Intersubjectivity.” Philosophy Today Spring: 78-87.

Bourdieu, Pierre. 1990. The Logic of Practice. Cambridge, MA: Cambridge University.

Branscomb, Louisa P. 1993. “Surrender, Healing, and the Mythic Journey.” Journal of Humanistic Psychology 33(4): 64-74.

Brown, Stephen W., and Teresa A. Swartz. 1989. “A Gap Analysis of Professional Service Quality.” Journal of Marketing 53: 92-98.

Celsi, Richard L., Randall L. Rose, and Thomas W. Leigh. 1993. “An Exploration of High-Risk Leisure Consumption through Skydiving.” Journal of Consumer Research 20 (June): 1-23.

Corrado, Marisa. 2002. “Teaching Wedding Rules: How Bridal Workers Negotiate Control Over Their Customers. Journal of Contemporary Ethnography 31 (1): 33-67.

Crossley, Nick. 2004. “The Circuit Trainer’s Habitus: Reflexive Body Techniques and the Sociality of the Workout”. Body and Society 10 (1): 37-69.

Crossley, Nick. 2005. “Mapping Reflexive Body techniques: On body Modification and Maintenance.” Body and Society 11 (1): 1-35

Crossley, Nick. 2006. “In the Gym: Motives, Meaning and Moral Careers.” Body and Society 12 (3): 23-50.

Dalleck, Lance C., and Len Kravitz. 2002. “The History of Fitness.” Idea Health and Fitness Source (January): 1-5.

DeJaegher, Hanne. 2015. "How We Affect Each Other; Michel Henry's 'Pathos-With' and the Enactive Approach to Intersubjectivity. Journal of Consciousness Studies 22 (1-2): 112-132.

Dellande, Stephanie, Mary C. Gilly, and John L. Graham. 2004. “Gaining Compliance and Losing Weight: The Role of the Service Provider in Health Care Services.” Journal of Marketing 68 (July): 78-91.

de Mello, Gustavo., Deborah J. MacInnis, and David W. Stewart. 2007. “Threats to Hope: Effects on Reasoning about Product Information.” Journal of Consumer Research 34 (2): 15361.

DePaulo, Bella M. and Jeffrey D. Fisher. 1980. “The Costs of Asking for Help.” Basic and Applied Social Psychology 1 (1): 23-35.

Dion, Delphine, Lionel Sitz and Eric Remy. 2011. "Embodied Ethnicity: The Ethnic Affiliation Grounded in the Body.” Consumption, Markets \& Culture 14 (3): 311-331. 
Dishman, Rod K. and M. Chubb. 1990. “Determinants of Participation in Physical Activity.” In Exercise, Fitness and Health: A Consensus of Current Knowledge Proceedings of the International Conference on Exercise, Fitness and Health edited, by C. Bouchard, R.J. Shepard, T. Stephens, J. Sutton, and B. McPherson, 75-108. Champaign, IL: Human Kinetics.

Fischer, Eileen, Cele C. Otnes, Linda Tuncay. 2007. Pursuing Parenthood: Integrating Cultural and Cognitive Perspectives on Persistent Goal Striving.” Journal of Consumer Research 34 (4): 425-440.

Fischer, Eileen, Cele C. Otnes, Brynn Winegard, Eric P.H. Li, and Sarah J.S. Wilner. 2009. “Are We There Yet? Co-producing Success and Failure in a "Consumer-Intensive” Service context." In Consumer Culture Theory, edited by John F. Sherry and Eileen Fischer, 101-113, London: Routledge

Firat, Fuat A., and Alladi Venkatesh. 1995. "Liberatory Postmodernism and the Reenchantment of Consumption.” Journal of Consumer Research 22 (December): 239-67.

George, Molly. 2008. "Interactions in Expert Service Work: Demonstrating Professionalism in Personal Training.” Journal of Contemporary Ethnography 37 (1): 108-131.

Ghent, Emmanuel. 1990. "Masochism, Submission Surrender.” Contemporary Psychoanalysis 26 (1): 108-136.

Glaser, Barney G. and Anselm L. Strauss. 1967. The Discovery of Grounded Theory. Chicago: Aldine.

Gollwitzer, Peter M. 1996. "Planning and Coordinating Action.” In Psychology of Action: Linking Cognition and Motivation to Behavior, edited by Peter M. Gollwitzer and John A. Bargh, 283-312. New York: Guilford.

Gunnlaugson, Olen and Mary Beth G. Moze. 2012. "Surrendering Into Witnessing: A Foundational Practice for Building Collective Intelligence Capacity in Groups.” Journal of Integral Theory and Practice 7 (3): 105-115.

Howson, Alexander. 2004. “The Body in Consumer Culture.” In The Body in Society, 93-119. Cambridge: Polity Press.

Huang, Szu-chi, Susan M. Broniarczyk, Ying Zhang, and Mariam Beruchashvili. 2015. "From Close to Distant: The Dynamics of Interpersonal Relationships in Shared Goal Pursuit.” Journal of Consumer Research 41 (5): 1252-1266.

Huffman, Cynthia, Sirinivason Ratneshwar, and David G. Mick. 2000. “Consumer Goal Structures and Goal-Determination Processes.” In The Why of Consumption: Contemporary Perspectives on Consumer Motives, Goals and Desires, edited by Sirinivason Ratneshwar, David G. Mick, and Cynthia Huffman, 9-35. New York: Routledge. 
IBISWorld. 2015. Industry Outlook. Personal Trainers. Available at http://clients1.ibisworld. com/reports/us/industry/print/industryoutlook.aspx?indid=4189. Accessed December 16, 2015.

IHRSA. 2012. “IHRSA Annual Trend Report.”. Accessed June 2013. http://cms.ihrsa.org/.

Karababa, Eminegul and Guliz Ger. 2011. "Early Modern Ottoman Coffeehouse Culture and the Formation of the Consumer Subject. Journal of Consumer Research 37 (February): 737-760.

Kraus, Hans andRuth P. Hirschland. 1954. "Minimum Muscular Fitness Tests in School Children.” Research Quarterly 25 (2): 178-188.

Levy-Navarro, Elena. 2009. “Fattening Queer History: Where Does Fat History Go from Here?” In the Fat Studies Reader, edited by Esther, D. Rothblum and Sondra Solovay, 15-22. New York: New York University Press.

Lloyd, Moya. 1996. "Feminism, Aerobics and the Politics of the Body.” Body and Society 2 (2): 79-98.

Luther, Claudia. 2011. “Jack LaLanne Dies at 96; Spiritual Father of U.S. Fitness Movement.” Los Angeles Times. January 24. http://www.latimes.com/local/obituaries/la-me-jack-lalanne20110124-story.html\#page=1

McCracken, Grant. 1986. “Culture and Consumption: A Theoretical Account of the Structure and Movement of the Cultural Meaning of Consumer Goods.” Journal of Consumer Research 13 (June): 71-84

McCracken, Grant. 1988. The Long Interview. Newbury Park, CA: Wadsworth.

Melton, Deana, Teresa K. Dail, Jeffrey A. Katula, and KarenM. Mustian. 2011. “Women’s Perspectives of PTs: A Qualitative Study.” The Sport Journal 14.

http://www.thesportjournal.org/article/women-s-perspectives-personal-trainers-qualitative-study.

Melton, Deana I. Jeffrey A. Katula, and Karen M. Mustian. 2008. “The Current State of Personal Training: An Industry Perspective of Personal Trainers in a Small Southeast Community.” Journal of Strength Conditioning Research 22 (3): 883-889.

Moisio, Risto and Mariam Beruchashvili. 2010. "Questing for Well-Being at Weight Watchers: The Role of the Spiritual-Therapeutic Model in a Support Group.” Journal of Consumer Research 36 (5): 857-875.

Moze, Mary Beth G. 2009. “A Theory of Surrender: Understanding Psychological Surrender with Comparison to Ego Defense.” Dissertation Abstracts International, 70B (04): 412.

Oliver, Kelly. 2004. “Witnessing and Testimony.” Paralax 10: 79-88. 
Pantzar, Mika and Minna Ruckenstein. 2015. “The Heart of Everyday Analytics: Emotional, Material and Practical Extension in Self-Tracking Market. Consumption, Markets \& Culture 18 (1): 92-109.

Parmentier, Marie-Agnes, and Eileen Fischer. 2011. "You Can’t Always Get What You Want: Unsustainable Identity Projects in the Fashion System.” Consumption, Markets \& Culture 14 (1): 7-27.

Penaloza, Lisa, and Alladi Venkatesh. 2006. "Further Evolving the New Dominant Logic of Marketing: From Service to the Social Construction of Markets.” Marketing Theory 6 (3): 299316.

Phillips, Barbara J. 2005. “Working Out: Consumers and the Culture of Exercise.” The Journal of Popular Culture 38 (3): 525-551.

Price, Linda L., and Eric J. Arnould. 1999. “Commercial Friendships: Service Provider - Client Relationship in Context.” Journal of Marketing 63 (4): 38-56.

Price, Linda L., Eric J. Arnould, and Patrick Tierney. 1995a. “Going to Extremes: Managing Service Encounters and Assessing Provider Performance.” Journal of Marketing 59 (April): 8397.

Price, Linda L., Eric J. Arnould, and Sheila L. Deibler. 1995b. “Consumers’ Emotional Responses to Service Encounters: The Influence of the Service Provider.” International Journal of Service Industry 6 (3): 34-63.

Rice, Emmett A., J. L. Hutchinson, and M. Lee. 1958. A Brief History of Physical Education. New York: The Ronald Press Co.

Sassatelli, Roberta. 1999. "Interaction Order and Beyond: A Field Analysis of Body Culture within Fitness Gyms.” Body and Society 5 (2-3): 227-48.

Schouten, John W. 1991. "Selves in Transition: Symbolic Consumption in Personal Rites of Passage and Identity Construction.” Journal of Consumer Research 17 (March): 412-25.

Scott, Maura L. and Stephen M. Nowlis. 2013. "The Effect of Goal Specificity on Consumer Goal Reengagement. Journal of Consumer Research 40 (October): 444-459.

Smith Maguire, Jennifer. 2001. "Fit and Flexible: The Fitness Industry, PTs and Emotional Service Labor.” Sociology of Sport Journal 18 (4): 379-402.

Smith Maguire, Jennifer. 2002. "Body Lessons: Fitness Publishing and the Cultural Production of the Fitness Consumer.” International Review for the Sociology of Sport 37 (3-4): 449-464.

Smith Maguire, Jennifer. 2008a. Fit for Consumption: Sociology and the Business of Fitness. New York, NY: Routledge 
Smith Maguire, Jennifer. 2006. "Exercising Control: Empowerment and the Fitness Discourse.” In Sport, Rhetoric, and Gender: Historical Perspectives and Media Representations, edited by Linda K. Fuller, 119-129. New York, NY: Palgrave Macmillan.

Smith Maguire, Jennifer. 2008b. "Leisure and the Obligation of Self-Work: An Examination of the Fitness Field.” Leisure studies 27(1): 59-75.

Smith Maguire, Jennifer. 2008c. "The Personal is Professional: PTs as a Case Study of Cultural Intermediaries.” International Journal of Cultural Studies 11(2): 211-229.

Spradley, James P. 1979. The Ethnographic Interview. New York: Holt, Rinehart, and Winston.

Statistica. Number of Members in Health and Fitness Clubs Worldwide by Region from 2009 to 2013 (in millions). (2015, Jan). Accessed May 22, 2015, from URL:

http://www.statista.com/statistics/273069/members-of-health-clubs-worldwide-by-region/

Swartz, Teresa A. and Stephen W. Brown. 1989. "Consumer and Provider Expectations and Experiences in Evaluating Professional Service Quality.” Journal of the Academy of Marketing Science 17 (2): 189-95.

Thompson, Craig J. 1997. "Interpreting Consumers: A Hermeneutical Framework for Deriving Marketing Insights from the Texts of Consumers’ Consumption Stories.” Journal of Marketing Research 34: 438-455.

Thompson, Craig J. and Elizabeth C. Hirschman. 1998. “An Existential Analysis of the Embodied Self in Postmodern Consumer Culture. Consumption, Markets \& Culture, 2 (4): 401447.

Tiebout, Harry M. 1949. "The Act of Surrender in the Therapeutic Process with Special Reference to Alcoholism.” Quarterly Journal of Studies on Alcohol 10: 48-58.

Valtonen, Anu. 2013. "Height Matters: Practicing Consumer Agency, Gender, and Body Politics.” Consumption, Markets \& Culture 16 (2): 196-221.

Wuest, Deborah A. and CharlesA. Bucher. 1995. Foundations of Physical Education. St. Louis, MO: Mosby.

Zayer, Linda Tuncay, Cele. C. Otnes, and Eileen M. Fischer. 2015. “The Nature and Implications of Consumers' Experiential Framings of Failure in High-Risk Service Contexts.” Journal of Service Research 18 (3): 303-317. 